\title{
Slow and incomplete histological and functional recovery in adult gluten sensitive enteropathy
}

\author{
J M M GREFTE, * J G BOUMAN, * J GROND, W JANSEN, * J H KLEIBEUKER* \\ From the Departments of *Gastroenterology and Pathology, University Hospital, Groningen, The Netherlands
}

SUMMARY To assess the course of recovery of gluten sensitive enteropathy in adults, histological and functional recovery was studied in 22 patients, aged 20-79 years. Biopsy specimens taken at the time of diagnosis were studied in 20; after adhering to a gluten free diet for nine to 19 (mean 14) months in 14 ; and after adhering to the same diet for $24-48$ (mean 34) months in 10 patients. Histological recovery was assessed morphometrically in the proximal jejunum. Mucosal linings significantly improved over time, but did not completely return to normal with a gluten free diet: at diagnosis the surface:volume ratio was $22 \%$ of normal, increasing to $48 \%$ and $66 \%$ after nine to 19 and $24-48$ months, respectively, of a gluten free diet. Disaccharidase activities progressively increased. After 24 48 months maltase, sucrase, and isomaltase had returned to normal in the proximal jejunum; they were still significantly decreased in the distal duodenum. Duodenal and jejunal lactase activities were both below normal after 24 to 48 months.

It is concluded that recovery of the intestinal mucosa of adults with gluten sensitive enteropathy during a gluten free diet continues beyond nine to 19 months and is still incomplete after two to four years. The recovery of disaccharidase activities extends from the distal to the proximal part of the small intestine, and is aligned to histological recovery.

Gluten sensitive enteropathy or coeliac sprue is characterised by severe villous atrophy of the small intestinal mucosa; it responds favourably to the withdrawal of dietary gluten. Gross villous architecture and absorptive cells are severely damaged, and many enzymes, necessary for the digestive-absorptive process, are severely depleted. This is especially true for brush border enzymes like the disaccharidases maltase, sucrase, isomaltase, and lactase. To what degree the mucosa will recover during a gluten free diet is still a matter of controversy: morphological changes occur and disaccharidases increase after gluten withdrawal. Most investigators have found that although some patients show complete histological and functional recovery during the diet, most still show some degree of histological and functional damage, even after adhering to the diet for several years. ${ }^{1-5}$

Within days or weeks of starting a gluten free diet a clinical response can be detected. This is also true for some of the histological and functional abnormalities: soon after gluten withdrawal the height of the mucosal surface cells increases ${ }^{6}$ and partial return to normal of organelles is observed. ${ }^{7}$ The recovery of the villous

Accepted for publication 17 March 1988 architecture is known to occur much more slowly, but so far no studies have emphasised the course of this slow recovery. Little is known with certainty about the rate and course of recovery of the disaccharidases and other brush border enzymes.

There is good evidence to suggest that the most severe histological damage is found in the proximal small intestine in untreated coeliac disease $\mathrm{e}^{28}$ and that during treatment, the most distal lesions recover first and to the greatest extent. ${ }^{2}$ Whether this is also true for the disaccharidases is not known.

In this study the long term course of histological and functional recovery in 22 patients with gluten sensitive enteropathy on a gluten free diet was investigated. The degree of recovery of disaccharidases at two different levels in the proximal small intestine was also compared.

\section{Material and methods}

This retrospective study comprised 22 patients (nine men and 13 women) with gluten sensitive enteropathy, diagnosed between 1965 and 1984. All patients were white and native Dutch. The mean age at time of diagnosis was 46 years (range 20-76). Diagnosis was based on clinical history, the demonstration of severe 
Table Details of diagnostic and follow up biopsy specimens

\begin{tabular}{|c|c|c|}
\hline Case No & $\begin{array}{l}\text { Follow up specimens } \\
\text { after nine to } 19 \\
\text { months on a } \\
\text { gluten free } \\
\text { diet }\end{array}$ & $\begin{array}{l}\text { Follow up specimens } \\
\text { after } 24 \text { to } 48 \\
\text { months on a } \\
\text { gluten free } \\
\text { diet }\end{array}$ \\
\hline $\begin{array}{l}1-5 \\
6-12 \\
13-18 \\
19-20\end{array}$ & $\begin{array}{l}6-12 \\
13-18 \\
21\end{array}$ & $\begin{array}{l}13-18 \\
19-20 \\
21 \\
22\end{array}$ \\
\hline
\end{tabular}

villous atrophy on dissection, and light microscopy, with concomitant impaired intestinal absorption shown by various tests (D-xylose test, vitamin A absorption test, Schilling test, and faecal fat excretion), coupled with a favourable clinical and histological response after starting a gluten free diet.

Diagnostic biopsy specimens were available from 20 patients; the two other patients had been diagnosed in other hospitals. Biopsy specimens of these two patients were re-examined at the time of referral and severe villous atrophy was found. Biopsy specimens were also available from 14 patients who adhered to a gluten free diet for a mean of 14 months (range nine to 19), and from 10 patients who had adhered to a gluten free diet for a mean of 34 months (range 24-48) (table). All these patients had strictly adhered to a gluten free diet, which was established from a dietary history by an experienced physician or a dietician. Excluded from this study were follow up biopsy specimens obtained less than nine months or more than four years after the start of the diet, and those of patients who were not known to have followed the diet strictly.

\section{DUODENAL-JEJUNAL BIOPSY SPECIMENS}

Mucosal biopsy specimens were obtained after an overnight fast, using a multipurpose suction biopsy capsule under fluoroscopic guidance. Two jejunal biopsy specimens were taken at about $10 \mathrm{~cm}$ distally and one duodenal specimen at about $10 \mathrm{~cm}$ proximally from the ligament of Treitz. One jejunal biopsy specimen was fixed in formalin for histological examination, the other two were immediately put on ice and subsequently stored at $-20^{\circ} \mathrm{C}$ until assayed for disaccharidase activities (within three weeks of collection).

\section{HISTOLOGY}

All biopsy specimens were re-examined by an experienced pathologist. To quantitate mucosal damage the surface:volume ratio of the mucosa was determined according to the method of Dunnill and Whitehead, ${ }^{9}$ recently validated by Corazza et al. ${ }^{10}$
Specimens were examined blind and twice with an interval of three months. There was a good correlation $(r=0.84)$ between the results of these two examinations. In the biopsy specimens of five normal subjects the mean $( \pm \mathrm{SEM})$ surface:volume ratio was 45.5 (7.6), which was well in accordance with the value found by Dunnill and Whitehead-46.0 (12.0). ${ }^{9}$

\section{INTESTINAL DISACCHARIDASE ACTIVITIES}

Mucosal activities of the intestinal enzymes maltase, sucrase, isomaltase and lactase were determined using the procedure described by Dahlqvist ${ }^{11}$ and expressed in units/gram protein $(\mathrm{U} / \mathrm{g})$. Palatinase was used as substrate to determine isomaltase activity. ${ }^{12}$ Normal values for the intestinal enzymes were obtained from the data of 49 white, native Dutch patients ( 25 women and 24 men, mean age 37 years, range 19-63), from whom a small-intestinal biopsy specimen had been obtained in our department between 1975 and 1984. All had normal mucosal morphology on microscopic examination and normal results of intestinal absorption tests, including disaccharide tolerance tests which were performed in selected cases. Another cause for the gastrointestinal symptoms was found in all cases. None of them had one of the following diseases, each of which has been described as possibly causing abnormal disaccharidase activities: cystic fibrosis, diabetes mellitus, exocrine pancreatic insufficiency, hyperthyroidism, anorexia nervosa. None of them had undergone gastrointestinal surgery.

Statistical evaluation of the results was performed using Student's $t$ test for unpaired results. P values of $\leqslant 0.05$ were considered to be significant.

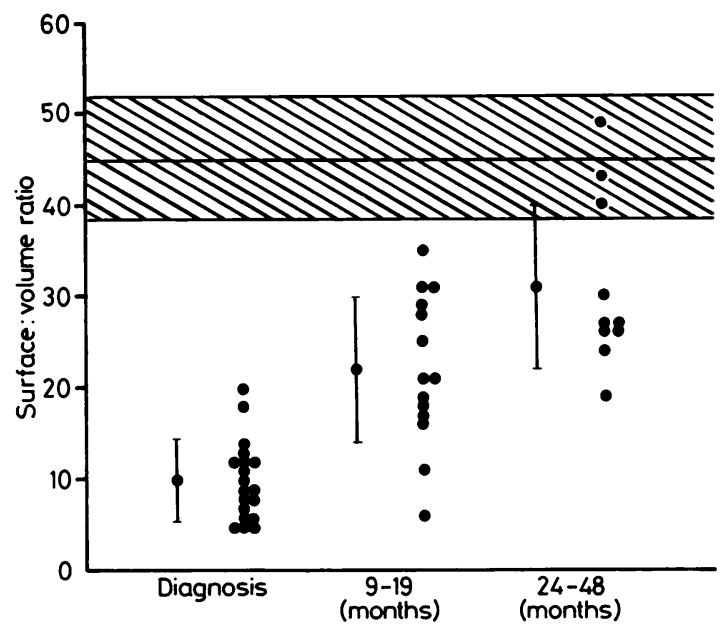

Fig 1 Surface:volume ratios (mean (SEM)) at diagnosis $(n=19)$ and after having followed a gluten free diet for nine to 19 months $(n=14)$ and $24-48$ months $(n=10)$ in 22 patients with gluten sensitive enteropathy, compared with control values $(n=5)$ ( $)$. 

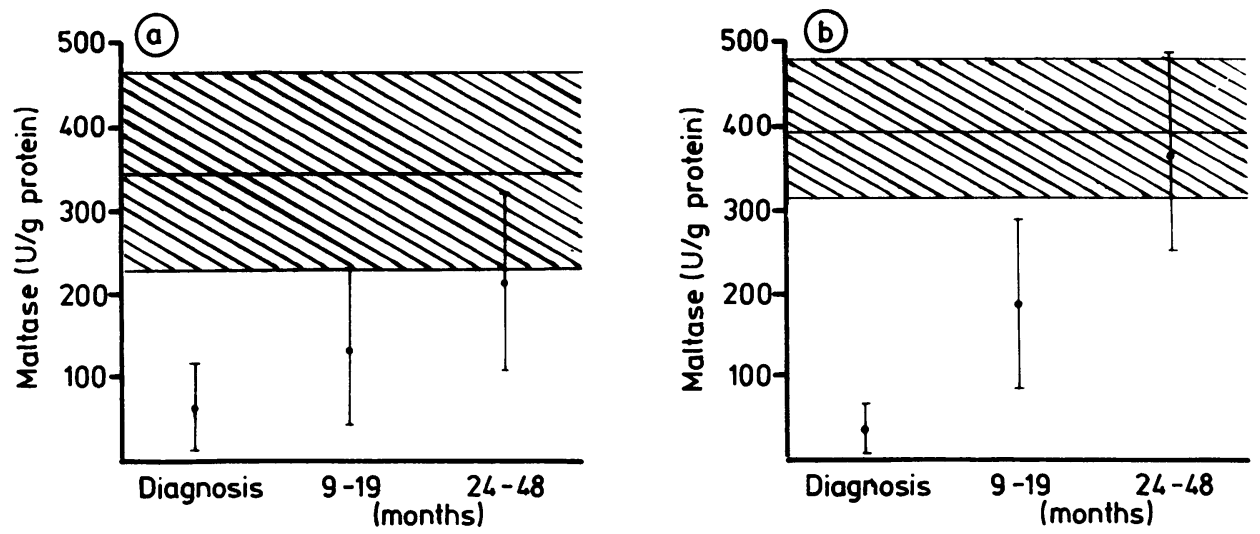

Fig 2 Mean (SEM) maltase activity in distal duodenum (a) and proximal jejunum (b) at diagnosis $(n=20)$ and after having followed a gluten free diet for nine to 19 months $(n=14)$ and 24 to 48 months $(n=10)$ in 22 patients with gluten sensitive enteropathy, compared with control values $(n=49)(\mathbb{N})$

\section{Results}

\section{HISTOLOGY (FIG 1)}

The surface:volume ratio could be determined in 19 of 20 available diagnostic biopsy specimens. The mean $( \pm$ SEM) ratio at the time of diagnosis was $10 \cdot 1(4 \cdot 3)$, which is $22 \%$ of the mean normal value. After having adhered to a gluten free diet for between nine and 19 months, the mean surface:volume ratio increased significantly to $21 \cdot 8(8 \cdot 2)$ or $48 \%$ of normal $(n=14)$. A further significant improvement occurred in patients who had followed the diet for between 24 and 48 months, but the ratio remained significantly lower than normal-that is, $30.9(9.5)$ or $68 \%$ of normal $(n=10)$.

\section{DISACCHARIDASE ACTIVITIES}

The activities of the disaccharidases maltase, sucrase, and isomaltase significantly increased, both in the proximal jejunum and in the distal duodenum after having followed a gluten free diet for between nine and 19 months. In the jejunum maltase increased from 42.9 (35.3), to $186.4(99.5) \mathrm{U} / \mathrm{g}$ protein (fig 2 ), sucrase from $14.2(7.6)$ to $56.9(47.4) \mathrm{U} / \mathrm{g}$ protein (fig 3), and isomaltase from $3.6(2 \cdot 8)$ to $14 \cdot 1(6.4) \mathrm{U} / \mathrm{g}$ protein (fig 4). In the duodenum maltase increased from 62.5 $(53.8)$ to $141.5(92.0) \mathrm{U} / \mathrm{g}$ protein (fig 2), sucrase from $19 \cdot 2(15 \cdot 3)$ to $33.8(24.6) \mathrm{U} / \mathrm{g}$ protein (fig 3 ), and isomaltase from $3.8(3.4)$ to $10.2(6.7) \mathrm{U} / \mathrm{g}$ protein (fig 4). Lactase activity also increased significantly in the proximal jejunum from $3.0(2.7)$ to $11.1(7.8) \mathrm{U} / \mathrm{g}$
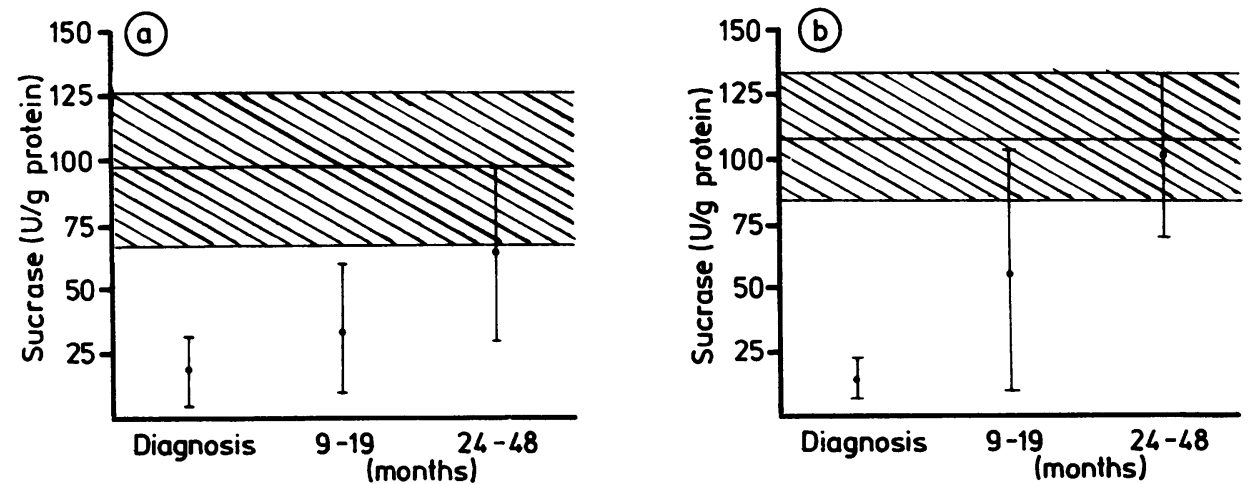

Fig 3 Mean (SEM) sucrase activity in distal duodenum (a) and proximal jejunum (b) at diagnosis $(n=20)$ and after having followed a gluten free diet for nine to 19 months $(n=14)$ and 24 to 48 months $(n=10)$ in 22 patients with gluten sensitive enteropathy, compared with control values $(n=49)(\mathrm{N})$ 

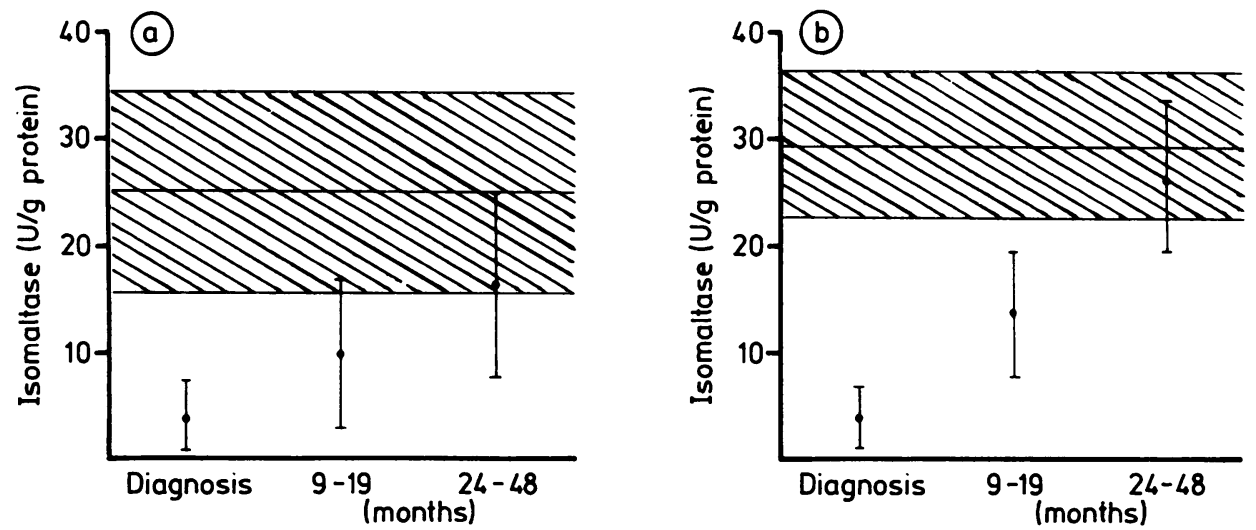

Fig 4 Mean (SEM) isomaltase activity in distal duodenum (a) and proximal jejunum (b) at diagnosis $(n=20)$ and after having followed a gluten free diet for nine to 19 months $(n=14)$ and 24 to 48 months $(n=10)$ in 22 patients with gluten sensitive enteropathy, compared with control values $(n=49)(\mathbb{Q})$

protein, but not in the distal duodenum: $3.8(4.3) v 8.9$ $(10.6) \mathrm{U} / \mathrm{g}$ protein (fig 5). The activities of all four enzymes were still significantly lower than normal after between nine and 19 months.

After 24 to 48 months a further significant increase of all enzyme activities was observed, with the exception of the activity of maltase in the distal duodenum (figs 2-5). In the proximal jejunum the activities of maltase, sucrase, isomaltase and lactase were 365.5 (117.7), 102.0 (32.1), 27.1 (6.5) and 35.8 (16.9) U/g protein, respectively. In the distal duodenum these values were $217.5(100 \cdot 4), 63 \cdot 2(32 \cdot 5), 17 \cdot 3(9 \cdot 2)$ and $18.9(12.3) \mathrm{U} / \mathrm{g}$ protein, respectively. The activities of maltase, sucrase, and isomaltase in the proximal jejunum were not significantly different from normal after 24-48 months; the activities of these three enzymes in the distal duodenum were still abnormal. Both distally and proximally to the ligament of Treitz lactase activity remained significantly lower than normal after 24-48 months of diet.

\section{Discussion}

The clinical response of patients with gluten sensitive enteropathy after starting a gluten free diet is observed within days to weeks, and this was also true for the patients in this study. The histological recovery of the proximal jejunal mucosa, however, seems to take much longer: we found a mean surface:volume ratio which was only $68 \%$ of normal in patients on the diet
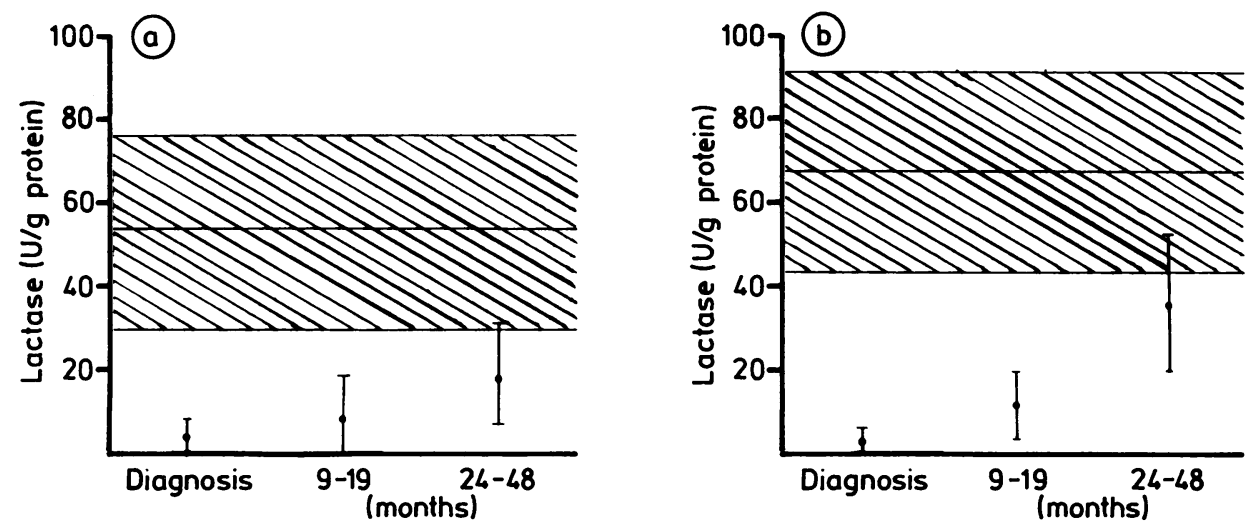

Fig 5 Mean (SEM) lactase activity in distal duodenum (a) and proximal jejunum (b) at diagnosis $(n=20)$ and after having followed a gluten free diet for nine to 19 months $(n=14)$ and 24 to 48 months $(n=10)$ in 22 patients with gluten sensitive enteropathy, compared with control values $(n=49)(\mathbb{\mathbb { S }})$ 
for between 24 and 48 months, although it had risen significantly during the first and second period after beginning the diet. The recovery of disaccharidase activity in the distal duodenum more or less followed the same pattern: the activities found after 24-48 months of a gluten free diet were still significantly different from control values. In the proximal jejunum, activities reached after $24-48$ months of dieting, did not differ significantly from normal, with the exception of lactase activity.

Most other investigators have reported similar results in respect of the degree of recovery during the continued use of a gluten free diet. ${ }^{1-5}$ To date none of the studies has specifically focused on the rate and course of the recovery. In this study we found that the process of recovery continues beyond nine to 19 months and may well continue beyond 24 to 48 months. The implication of this finding is that adult patients with substantial functional and histological abnormalities when rebiopsied after less than two years of a gluten free diet should not be suspected automatically of not adhering to their gluten free diet properly.

Dissanayake $e t a l^{13}$ found that full histological and functional recovery is possible within 30 months in adult patients, provided that a strictly gluten free diet is followed. When the biopsy during the gluten free diet was found to be abnormal in our patients a scrupulous investigation into the patient's dietary habits and methods of food preparation was performed by an experienced physician or dietician. None of the patients, reported in this paper, was found to have ingested gluten. Although some of our patients may still have made minor dietary errors, which escaped from notice, it is unlikely that so few of our patients would not have kept strictly to a gluten free diet. The finding of Dissanayake et al thus cannot be confirmed.

Most previous investigations $\mathrm{s}^{3-514}$ have shown a clear difference between the recovery of lactase activity, compared with the recovery of the other disaccharidases. Lactase recovery seems to be slower and seldom returns to normal values. Although Dissanayake $e t a l^{13}$ found that lactase activity did not differ significantly from normal after $\mathbf{3 0}$ months of a strictly gluten free diet, the lactase activity found was only $47.2 \%$ of normal in the proximal jejunum. At the time of diagnosis we found that the lactase activity in the proximal jejunum as well as in the distal duodenum was relatively more depressed than the other enzyme activities. In the distal duodenum lactase activity also remained low during the first nine to 19 months of gluten free diet; the other disaccharidase activities increased significantly during that period. The lactase activity at that location after 24 to 48 months of dieting was only $35.6 \%$ of normal, compared with about $65 \%$ for the other disaccharidases. At that time the lactase activity in the proximal jejunum was $53.3 \%$, which was also still significantly different from normal. Lactase therefore seems to be the most severely depressed disaccharidase in gluten sensitive enteropathy, which shows only a late and incomplete recovery, compared with the other disaccharidases in the distal duodenum as well as in the proximal jejunum after 24-48 months of gluten free diet. Nevertheless, the possibility cannot be excluded that even lactase activity may recover completely when a gluten free diet is adhered to for a longer period of time.

In untreated gluten sensitive enteropathy mucosal damage is more severe in the proximal small intestine than distally. ${ }^{28}$ Once on a gluten free diet, the histological recovery of the mucosa is more rapid and more complete in the distal parts of the small intestine than proximally, ${ }^{2}$ which is supposed to be due to the fact that the proximal part of the small intestine is more heavily exposed to gluten.

As it is known that functional recovery parallels histological recovery, ${ }^{35}$ it would be expected that the recovery of disaccharidase activity in the small intestine follows the same pattern. We investigated the recovery of the disaccharidase activity in both the proximal jejunum and the distal duodenum, and even though the distance between the two biopsy sites was only about $20 \mathrm{~cm}$, there was indeed a noticeable difference: recovery of disaccharidase activities in the proximal jejunum after 24-48 months of a gluten free diet was complete, with the exception of lactase activity; in the distal duodenum all disaccharidase activities remained moderately to severely depressed. The increase of disaccharidase activities was more significant in the proximal jejunum in the first nine to 19 months of a gluten free diet than in the distal duodenum ( $p$ values for maltase, sucrase, isomaltase and lactase were respectively, $<0.001,0.001,0.001$, 0.001 and $<0.01,0.05,0.01,>0.05$ ). Thus recovery of disaccharidase activities also seemed to extend distally to proximally in the small intestine in response to a gluten free diet. This lends further support to the suggestion of MacDonald et al that this pattern of recovery is the main reason why we usually find excellent clinical responses once a gluten free diet is started, although duodenojejunal biopsy specimens are still very abnormal.

In conclusion, we found that (i) histological and functional recovery in gluten sensitive enteropathy continues beyond nine to 19 months after starting a gluten free diet and is still incomplete after 24 to 48 months; (ii) whereas histological abnormalities in the proximal jejunum persist after 24-48 months, disaccharidase activities have returned to normal with the exception of lactase activity; (iii) lactase activity is mose severely depressed compared with other disaccharidases at the time of diagnosis and remains so 
during a gluten free diet; (iv) recovery of disaccharidase activities extends from the distal to the proximal parts of the small intestine, in conjunction with histological recovery.

\section{References}

1. Bolt RJ, Parrish JA, French AB, Pollard HM. Adult coeliac disease. Histologic results of long-term low gluten diet. Ann Intern Med 1964;60:581-6.

2 MacDonald WC, Brandborg LL, Flick AL, Trier JS, Rubin CE. Studies of celiac sprue. IV. The response of the whole length of the small bowel to a gluten-free diet. Gastroenterology 1964;47:573-89.

3 Welsh JD, Zsiesche OM, Anderson J, Walker A. Intestinal disaccharidase activity in celiac sprue. Arch Intern Med 1969;123:33-8.

4 Berg NO, Dahlqvist A, Lindberg T, Norden A. Intestinal dipeptidases and disaccharidases in celiac disease in adults. Gastroenterology 1970;59:575-82.

5 Pena AS, Truelove SC, Whitehead R. Disaccharidase activity and jejunal morphology in coeliac disease. $Q J$ Med 1972;41:457-76.

6 Yardley JH, Bayless TM, Norton JH, Hendrix TR. Celiac disease. A study of the jejunal epithelium before and after a gluten-free diet. $N$ Engl J Med 1962;267:1173-9.

7 Peters TJ, Jones PE, Wells G. Analytical subcellular fractionation of jejunal biopsy specimens: enzyme activities, organelle path- ology, and response to gluten withdrawal in patients with coeliac disease. Clin Sci Mol Med 1978;55:285-92.

8 Stewart JS, Pollock DJ, Hoffbrand AV, Mollin DL, Booth CC. A study of proximal and distal intestinal structure and absorptive function in idiopathic steatorrhoea. $Q J$ Med 1967;36:425-44.

9 Dunnill MS, Whitehead R. A method for the quantitation of small intestinal biopsy specimens. J Clin Pathol 1972;25:243-6.

10 Corazza GR, Frazzoni M, Dixon MF, Gasbarrini G. Quantitative assessment of the mucosal architecture of jejunal biopsy specimens: a comparison between linear measurement, stereology and computer aided microscopy. J Clin Pathol 1985;38:765-70.

11 Dahlqvist A. Assay of intestinal disaccharidases. Anal Biochem 1968;22:99-107.

12 Dahlqvist A, Auricchio S, Semenza G, Prader A. Human intestinal disaccharidases and hereditary disaccharide intolerance. J Clin Invest 1963:42:556-62.

13 Dissanayake AS, Truelove SC, Whitehead R. Jejunal mucosal recovery in coeliac disease in relation to the degree of adherence to a gluten-free diet. $Q J$ Med 1974;43:161-85.

14 O'Grady JG, Stevens FM, Kean R, et al. Intestinal lactase, sucrase and alkaline phosophatase in 373 patients with coeliac disease. $J$ Clin Pathol 1984;37:298-301.

Requests for reprints to: $\mathbf{J} \mathbf{H}$ Kleibeuker, Department of Internal Medicine, University Hospital, PO Box 30.001, 9700 RB Groningen, The Netherlands. 